\title{
Multiculturalism Education for Refugees in Transit
}

\author{
Dewi Sari Wahyuni ${ }^{1}$ Eka Pasca Surya Bayu ${ }^{2}$ \\ ${ }^{1,2}$ Doctoral Students, Padang State University
}

\begin{tabular}{|c|c|}
\hline ARTICLE INFO & ABSTRACT \\
\hline Article history: & \multirow{10}{*}{$\begin{array}{l}\text { In non-formal classroom during their waiting time ir } \\
\text { transit, refugees often found it difficult to have dynamic } \\
\text { teamwork with others from diverse sociocultural. Thing } \\
\text { considered small stuffs for some turned out to be } \\
\text { problematic issue to others. Their various background } \\
\text { home countries, ethnicities, previous socioeconomic } \\
\text { status added to the exclusion and specific group } \\
\text { connection with tendency of being unsettled when they } \\
\text { were obligated to mix with their fellows outside thei } \\
\text { comfort group. Even though most of these people have } \\
\text { experienced in moving around from one country intc } \\
\text { another, their marginal life was not a much of help to } \\
\text { their socialization with people outside of thei } \\
\text { community. Promoting multicultural education which } \\
\text { values diversity and includes the perspectives of a variety } \\
\text { of cultural groups on a regular basis took longer time tc } \\
\text { decrease prejudice, tolerate changing habits and eliminate } \\
\text { gender bias. }\end{array}$} \\
\hline Received Mar 02, 2019 & \\
\hline Revised Sep 17, 2019 & \\
\hline & \\
\hline Keywords: & \\
\hline $\begin{array}{l}\text { Multiculturalism Education, } \\
\text { Refugees, } \\
\text { Transit }\end{array}$ & \\
\hline Clonflict of Interest: & \\
\hline None & \\
\hline Funding: & \\
\hline None & \\
\hline
\end{tabular}

Corresponding Author: Dewi Sari Wahyuni ${ }^{1}$, Doctoral Students, Padang State University. Jalan Prof. Dr. Hamka Air Tawar Padang, Sumatera Barat Mobile Phone. +62-8117522854 ${ }^{1}+62-085274208020^{2}$. Email: dewisariwahyuni@gmail.com

Copyright (C) Association of Language Teachers in Southeast Asia. All rights reserved

\section{Introduction}

United Nations High Commissioner for Refugees (UNHCR) - The UN Refugee Agency named people who they give assistance as Persons of Concern and divides them into: refugee, internally displaced person, returnees, stateless people, and asylum seeker. All of these people are referred to as Persons of Concern by UNHCR.

A refugee is someone who runs away from his or her home country due to the fact that experiencing being exterminated, driven away or subjugated based on their membership in a religious, ethnic, social, or racial group, conflict carried on by force of arms both between nations or parties within a nation or violent act or proceeding. As in logical, refugees are incapable to revert to their own home country or they are in fearful to even consider doing it. Almost $67 \%$ of refugees in the world are from Syria, Afghanistan, South Sudan, Myanmar and Somalia.

An internally displaced person, or IDP, is someone who forcefully moved from their home to other places such as adjacent area, schools, settlement, camps, woodlands and terrains and those places are still within their home countries. UNHCR mostly takes care of these IDPs people who are being forced out by 
internal dissension and natural dissasters. They are different from refugees, who are protected by international law or eligible and allowed to get various aids because IDPs are legitimately protected by their own government. The biggest numbers of IDPs are in countries such as Colombia, Syria, Democratic Republic of the Congo and Somalia.

Being a refugee and then decide to return to their home countries for various reasons make them as a returnee. This decision can sometimes be a traumatic experience or it even results better life when their home countries have recover from whatever conflicts they had previously. The return is possibly to happen within months, years or even decades after they flee and there is also a possibility that a refugee will never be back to their home country.

A stateless person is someone who does not belong to any of countries citizenship. This legality between a government and an individual within a country makes it possible to grant an individual the rights to be involved in political, economic, and social activities as per their own responsibilities bestowed upon both government and this individual. There are many reasons for an individual to lose his or her own state. Some of them are sovereignity, legality, technicality or administrative decisions or oversights. However, The Universal Declaration of Human Rights emphasized that everyone has the right to a nationality.

There are 14,405 total number of refugee in Indonesia from Afghanistan, Myanmar, Somalia, Sri Lanka, Nigeria, Iraq and others (UNHCR Factsheet, 2016). The ones that transit in Indonesia are people who are also called by International Organization that involves in taking care of those marginal people is International Organization for Migration (IOM) - as 'irregular migrants'. Irregular migrant is a person who, owing to unauthorized entry, breach of a condition of entry, or the expiry of his or her visa, lacks legal status in a transit or host country. It also includes people who have entered a transit or host country legally but have stayed for a longer period than authorized or subsequently taken up unauthorized employment. The term "irregular" is preferable to "illegal" because the latter carries a criminal connotation and is seen as denying migrants' humanity (Perruchoud and Redpath, 2011).

The ones that transit in Indonesia both can be considered as refugee and asylum seekers. The differentiation from refugees and asylum seekers status by United Nations High Commissioner for Refugees (UNHCR) is merely based on the process of their registration under UNHCR protection. An asylum-seeker is someone who is seeking international protection whose request for protection is under processing. Not every asylum seeker will eventually be given status as a refugee, but every refugee is once was an asylum seeker (Wahyuni and Fatdha, 2018).

In this article, all of them; refugees, asylum seekers and irregular migrants are called refugees to be simplified. The students were some of refugees who attended classes and teachers provided by IOM.

\section{Literature Review}

Refugees various background; home countries and cultural practices added to the exclusion and specific group connection with tendency of being unsettled when they were obligated to mix with themselves not to mention with the local people. Even though most of these refugees have experienced in moving around from one country into another, their marginal life was not a much of help to their socialization with people outside of their community (Wahyuni and Fatdha, 2018).

Praxis and practice of multicultural education as embedded in curriculum and or hidden are believes to be one of solution of problems occurred in classes for refugees. Multicultural education approaches had contributed astoundingly to focus on the special need of refugee. Despite the emergence of far-right organizations and what critics say harsh immigration policies, multiculturalism is still alive and well in the land down under (Hermawan, 2019). Developing multicultural awareness which concerns on understanding the others' culture and intercultural competence which is to manage relations with others will help them to understand and to apply responsibility, tolerance and inclusion (Etsuko Toyoda, 2016).

Multicultural education is education that values diversity and includes the perspectives of a variety of cultural groups on a regular basis. Its proponents believe that children of color should be empowered and that multicultural education benefits all students (Banks, 2014, 2015). Multicultural understanding is an approach that helps to create reconsiliation in the classroom for refugees where diversity is obvious and must be faced. The frame of these multicultural understanding in educational practices is getting more common. This multicultural understanding would eliminate prejudice toward other people from different background (King, Perez, \& Shim, 2013).

Multicultural education grew out of the civil rights movement of the 1960s in America and the call for equality and social justice for women and people of color (Gollnick \& Chinn, 2017). Multicultural education covers socioeconomic status, ethnicity, and gender issues. The trend in multicultural education elevated for not only ethnicity as a focus but also touches socioeconomic status, gender, religion, disability, gender, sexual orientation, and other forms of differences (Koppelman, 2017). Kopplement expanded that some 
might think that multicultural education only refers to students of color in America, on the other hand, it was all students, the majority ethnicity students were possible to have beneficiary from multicultural education.

One of the foundational values of multicultural education, social justice, is longed for decreasing prejudice and having fairness on pedagogy as core components (Banks, 2014, 2015). The value on decreasing prejudice can be achieved by teachers having implemented particular activities in the classroom to reduce refutation and stereotyped opinion by one's ethnicity towards others. Fairness in pedagogy deals with alteration or adjustment in teaching to embed suitable materials and learning strategies for both genders and diverse ethnic groups. Culturally relevant teaching is an important aspect of multicultural education (Gollnick \& Chinn, 2017). Teacher connects him or herself and materials with students' cultural background.

Knowing and getting familiar with students' community and the place where they live help teachers to comprehend more on their ethnic and cultural backgrounds (Banks, 2014; Gollnick \& Chinn, 2017). It was suggested that one of the approach for teachers is teachers' visit to the student's houses and social relationships with students' community members. Hence, teachers know a lot about to learn more about their cultural and ethnic background so that they can incorporate this knowledge into their teaching (Moll \& González, 2004). However, having such kind of social relationship may not all the time eliminate prejudice between ethnic among teacher - student and student -student (Frankenberg \& Orfield, 2007). The prejudice is possibly to decrease when the relations are getting better as students share their personal worries, successes, failures, coping strategies, interests and etcetera to each other. Revealing ones' personal information about themselves, make them more likely to be discerned as a single human than merely as members of a community as they share the same hopes, worries, and feelings. Personal information sharing is useful to disentangle in-group/out-group and we/they barriers.

Promoting non bias gender education is also a part of multicultural education. Social perspective on gender concerns on diverse social context where their upbringing takes place whether they are families, families, peers, school, and the media. Parents in common shape boys and girls to have different types of engagement in playing and doing activities (Leaper \& Farkas, 2015). They give girls dolls to play with and when they get older, they are assigned with baby-sitting duties and house chores. They are expected to be more caring and sensitive than boys. They spend more time with their mother and domestic tasks, while it will be considered as normal when fathers spend more time playing with their sons than their daughters. Boys are bestowed freedom more than that of offers to the girls. Peers also reward and punish gender-related behavior (Rubin, Bukowski, \& Bowker, 2015). In elementary level, boys the segregation teamwork will bring in more peaceful classroom situation. Peers play an especially important gender-socializing role, teaching each other what is acceptable and unacceptable gender behavior Eleanor Maccoby $(1998,2007)$.

\section{Method}

The research applied ethnography method and focused on refugees as students who joined classes at the community housings provided by IOM and appointed by Immigration Office. The participants are teachers, students, parents and random refugees living in the community housings, accommodation provided for them. This ethnographic methodology of research studied experiences and interactions teachers, refugee students and their community inside and outside classrooms from 2015 to 2018.

In depth interview were carried out to 5 focal points (considered as representatives for different ethnicities) and participant observation was conducted to different classrooms; children, teenager (mixed boys and girls) and three adult classes (women, men, mixed women and men) and number of students range from 10 to 20 .

\section{Results and Discussion}

\subsection{Prejudice}

Prejudice among refugees often caused conflicts in classrooms which were located in the community housings where they were temporarily in indefinite time accomodated. People from different home countries group themselves and reluctant to include others. They ignored to work in group with people from different home countries. Students came to teacher telling that they did want to work in the same group with other students for coming from different countries, judging others for having different values because of their origin, having different religions or even when they have similar religion; different sects were also a problem for executing unsimilar way of praying. What occurs in ones' culture is considered as natural and true while thing occurs in other cultures is unnatural and incorrect behavior because they side with their own cultural group, and tend to have earn their enmity against other cultural groups (Brewer \& Campbell, 1976; Campbell $\&$ LeVine, 1968).

Multicultural understanding can be the golden mean to the conflict arouse between refugees in the classroom situation. For these refugees come from different countries, and some even had experiences moving from one country into another before they arrived in Indonesia, diversity is unavoidable. The understanding of nature 
of them such as culture other than one's own in education allows them to neutralize their perspective to others. The majority refugee derived from similar home country is dominant and believe that they have superiority over another. They treated other refugees differently based on their race and ethnicity, religion and its sect.

Social perseptions among refugees also touched biological differences between people. For some group of people from specific countries who admire the brighter color of skin, for example, would annoy and even disparage people with darker skin which are the characteristics of other refugees from other specific countries. This happened mostly to the ones that were just newcomer, migrating from small town or village and directly went to Indonesia or just transit in one or two countries previously in a short time without experiencing migrating from one to other countries in a long time before finally transiting in Indonesia.

Teacher can improve students' lives and educational orientation by building bridges to their community. In this case, teachers luckily taught in the classroom located in the community housings where the students lived. The classes were more flexible as it was categorized as non-formal education provided by IOM for these students were not yet permitted for joining public school. Only teachers that can diffuse themselves with their student's community that they face everytime they came to the classrooms survived.

Teachers employed multicultural education both in the content of the lessons and ensured that students discuss about different countries, different ways of living, different manners and etcetra. Hidden curriculum was also employed that students get the idea of differences should not be an obstacle to work together with others as they are all refugees and they had to tolerate each other before being able to integrate or to have inclusion to Indonesian as local people. To local people, they were all immigrant no matter from what countries they fleed as they were considered as outsiders and hitchhikers.

\subsection{Changing Habit}

Refugees from specific countries had tendency to sleep during the day and stay up late at night even until dawn. It was because the adjustment of their home countries differences of their home countries' or the last countries' time that they stay previously with Indonesian time. However, some who had been in Indonesia for a quite a long time said that it was because they had nothing to do during the day and in that their own country they also woke up in the morning and slept at night like what other refugees and almost normal Indonesian people do. The opponents from different countries considered them as lazy for there were activities supported by both international organizations; UNHCR and IOM that were possibly executed during the day.

They are so noisy. They shout and scream while we are sleeping. We need to sleep and we cannot because of the noise they make. Their children run throughout the aisle in front our rooms. It is too much...

People coming from similar home countries also had differences. The long-time refugees had adjusted themselves into their own new way of living and created new habits such as woke up late at night and slept during the day. They complained that others did not let them to have a nice sleep. Meanwhile, the newcomers after dealing with their extreme tiredness and other physical effects felt by after a long flight or journey across several time zones were willing to come to any classes, attend and participate in any activites held at the community housing as well as outside. This was due to collectivism which consists of a set of values that support the group. Personal goals are subordinated to preserve group integrity, interdependence of the group's members, and harmonious relationships (Masumoto \& Juang, 2017).

Other ethnic who had almost similar habit with Indonesian judged the considered 'lazy' group of people because of their difference in ethnicity which was based on their own judgement.

They are lazy and crazy. They sleep in the morning and wake up at night. Their children were playing around at 2 a.m. make us awake and after that we cannot sleep. We have to wake up in the morning and do our activities during the day. But they get angry with us and tell us we make noise when they are sleeping. We do not do anything wrong...

Since this almost similar group had similar tradition with Indonesian, they are more familiar with local people. They can learn local language smoothly and as their physical appearance are even look like the local, they blended in. This was also the case that leads to a breach of harmonious relationship among refugees from even similar home countries with different ethnicity.

The problem for having different time to sleep also affected the classroom schedule and attendance. Some demanded that the classroom should be scheduled at night; otherwise they would not come to the class. Others opposed to the time proposed and demanded to have the class during the day. Based on the working hour of IOM, the teachers for non-formal classes should only teach during working hours. Automatically, 
night classes were not an option. However, to accommodate the night-owl people, the informal classes were also empowered with teachers from their own people.

\subsection{Gender}

In many countries, males have far greater access to educational opportunities, more freedom to pursue a variety of careers, and fewer restrictions on sexual activity than do females (UNICEF, 2016). This condition also happened to refugees. Some women were not permitted by their husbands, father or brother to study at all although most of the girls were allowed to. And even when the women and girls were allowed to study, the men proposed a requirement that they might not be put in the same class with the boys or men.

Since a number of classrooms were limited in each of community housings, the schedule was so tight and in order to avoid overlapping classes' occupancy, it was hardly to fulfill the men's requirement. Teachers were also in hectic schedule for they had to mobilize to community housings which located quite far from each other. The situation resulted in the less number of girls and women (in mixed class) studying in the classroom. It took years when they finally compromised and more and more female students started coming to classes.

In a specific class where only women segregation can be fulfilled, many did not attend the class full time, they came late to the class, asked for leaving the class earlier, being called by their husbands or children for household things such as taking care of their babies and doing house chores when classes took place. Girls were also responsible for taking care their little siblings and house chores while boys were relatively free from them.

Men from mixed classes often had a clash with women behavior that they think against their culture and values as men primarily are socialized and schooled to work in the public sphere and females are mainly socialized to remain in the private world of home and child rearing. Any deviations from this traditional masculine and feminine behavior are severely disapproved of. Even a small act such as joking and laughing was considered inappropriate as women.

A woman should not laugh like that. She should not joke like that. She should have watched her words. Her husband should teach her a lesson. I will not let my wife to do that...

As a consequence, teachers often just put them in the same sex group and avoid competition between groups. Whenever it was possible, each student would be grouped as single sex group and similar ethnicity, but when it was not possible, they were often grouped based on gender for it was safer. Meanwhile, the segregated classes (men only and women only) had fewer conflicts other than ethnicity and cultural belief. The attendace rate was higher for these single sex classes compared to mixed sex. Men classes had highest rate of attendance records. Both of these segregated classes were relatively peaceful and they worked more dynamic compared to the mixed class. Students in children and teenagers classes also showed similar tendency with adult mixed sex classes in term of ethnicity. However, male and female students were able to work cooperatively when they came from single ethnicity. They tended to be offended with both gender from the diverse one. When given projects, teacher often put them in group with the same ethnicity and if possible when they have less number of group members, they would be grouped as both single ethnicity and gender to anticipate chaos and disturbance to classroom activities.

\section{Conclusion}

Refugees in Indonesia should wait in indefinite time to be finally resettled. During this long term waiting time, they need to be provided with at least basic education as one of human rights. The efforts attempted to negotiate these refugees to join host country public school will not be as simple as it seems. The refugees should be prepared or they should prepare themselves to the inclusion. Anticipating the problem that might be drawn when they integrate with local people will be much a help when they have improve their relationship among them in refugee community. It is not only the responsibility of people from the host country to welcome them as they should also adjust themselves with the place they live temporarily and there is a chance that they will spend longer time or perhaps forever before they are resettled to their destination country.

This community had been given chance to have non-formal education. Through these non-formal classrooms, multicultural education had already embedded and hidden in the curriculum. Previously, they who are from different home countries live alongside one another in community housings and each groups did not really engange or interact with each other. The problems came up to the surface when this diverse group were put in classrooms where they had to interact and even work together. Rejection, chaos, protest and inconducive situations were staining activities in the classroom. 
After students obtain their understanding in multicultural, then, cross-cultural understanding will be the next steps. They have to understand and familiar with their differences before being able to compare or contrast themselves with dominnat culture in host country. In the end, it is expected that a deep understanding and respect for all cultures will be gained so that eliminating prejudice, tolerating changing habit and diminishing gender bias between refugees can be anticipated before they have intercultural communication with local people on mutual exchange of ideas and cultural norms. In the intercultural society, no one should be left behind for they can learn from one another and grows together.

\section{References}

Amthor, F.R \& Roxas, K. (2016). Multicultural Education and Newcomer Youth: Re-Imagining a More Inclusive Vision for Immigrant and Refugee Students. A Journal of the American Educational Studies Association. 52(2).

Banks, J.A. (2014). Introduction to Multicultural Education (5th ed.). Upper Saddle River, NJ: Pearson.

Banks, J.A. (2015). Cultural Diversity and Education (6th ed.). Upper Saddle River, NJ: Pearson.

Brewer, M.B., \& Campbell, D.I. (1976). Ethnocentrism and Intergroup Attitudes. New York: Wiley.

Campbell, D.T., \& LeVine, D.T. (1968). Ethnocentrism and Intergroup Relations. In R. Abelson \& others (Eds.), Theories of Cognitive Consistency. Chicago: Rand McNally.

Etsuko, T. (2016) Intercultural Knowledge, Awareness and Skills Observed in a Foreign Language Classroom, Intercultural Education, 27:6, 505-516.

Frankenberg, E., \& Orfield, G. (Eds.) (2007). Lessons in Integration. Charlottesville, VA: University of Virginia Press.

Gollnick, D.M., \& Chinn, P.C. (2017). Multicultural Education in a Pluralistic Society (10th ed.). Upper Saddle River, NJ: Pearson.

Hermawan, Ary. (2019). Making Multiculturalism Work in Australia, One Refugee at a Time. Jakarta: The Jakarta Post. (March 16, 2019).

King, P. M., Perez, R. J., \& Shim, W.-J. (2013). How College Students Experience Intercultural Learning: Key Features and Approaches. Journal of Diversity in Higher Education, 6(2): 69-83.

Koppelman, K.L. (2017). Understanding Human Differences (5th ed.). Upper Saddle River, NJ: Pearson.

Leaper, C. (2015). Gender Development From a Social-Cognitive Perspective. In R.M. Lerner (Ed.), Handbook of Child Psychology and Developmental Science (7th ed.). New York: Wiley.

Maccoby, E.E. (1998). The two sexes: Growing up apart, coming together. Cambridge, MA: Harvard University.

Maccoby, E.E. (2007). Historical overview of socialization research and theory. In J.E. Grusec \& P.D. Hastings (Eds.), Handbook of socialization. New York: Guilford.

Matsumoto, D., \& Juang, L. (2017). Culture and Psychology (6th ed.). Boston: Cengage.

Moll, L.C., \& González, N. (2004). Engaging life: A Funds of Knowledge Approach to Multicultural Education. In J.A. Banks \& C.A.M. Banks (Eds.), Handbook of Research on Multicultural Education (2nd ed.). San Francisco: Jossey-Bass.

Rubin, K.H., Bukowski, W.M., \& Bowker, J. (2015). Children in Peer Groups. In R.M. Lerner (Ed.), Handbook of Child Psychology and Developmental Science (7th ed.). New York: McGraw-Hill.

Wahyuni, D.S. \& Fatdha, T.S.S.E. (2018). ICT and education for Refugees in Transit. Southeast Asia Language Teaching and Learning Journal (SALTeL Journal). 2(2)8-14 DOI: 1035307/SALTeLV2i2.27 